\title{
CARACTERÍSTICAS DO COMITÊ DE AUDITORIA: UM ESTUDO NAS EMPRESAS LISTADAS NA BM\&FBOVESPA
}

\author{
CHARACTERISTICS OF AUDIT COMMITTEE: A STUDY IN LISTED \\ COMPANIES AT BM\&FBOVESPA
}

\author{
VANDERLEI DOS SANTOS \\ Doutorando do Programa de Pós-Graduação em Contabilidade da \\ Universidade Federal de Santa Catarina (UFSC). Professor da \\ Universidade do Estado de Santa Catarina (UDESC). Endereço: \\ Universidade Federal de Santa Catarina, Campus Reitor João David \\ Ferreira Lima, s/n, Trindade / 88040-900 | Florianópolis/SC / Brasil. \\ E-mail: vanderleidossantos09@gmail.com
}

\section{CAMILA FRANCIELI SCHMEIDER}

Especialista em Controladoria e Finanças pela Universidade do Estado de Santa Catarina (UDESC). Endereço: Rua Dr. Getúlio Vargas, 2822, Bela Vista / 89140-000 / Ibirama/SC / Brasil.

E-mail: camila.schmeider@yahoo.com.br

\section{PAULO ROBERTO DA CUNHA}

Doutor em Ciências Contábeis e Administração pela Universidade Regional de Blumenau (FURB). Professor do Programa de PósGraduação em Ciências Contábeis da Universidade Regional de Blumenau (PPGCC/FURB) e da Universidade do Estado de Santa Catarina (UDESC). Endereço: Rua Antônio da Veiga, 140, Sala D 202, Bairro Victor Konder / 89012-900 / Blumenau/SC / Brasil.

E-mail: pauloccsa@furb.br

\section{RESUMO}

O estudo objetivou verificar as características de tamanho, independência e expertise dos comitês de auditoria das empresas listadas na BM\&FBovespa nos anos de 2010 a 2013. Dentre as 407 empresas listadas na bolsa de valores, apenas 68 delas possuem comitê de auditoria devidamente formado em algum período analisado. O ano de 2013 apresentava 59 empresas com comitê de auditoria, o maior número encontrado, o que representa apenas $14,50 \%$ da população. Os principais resultados mostraram que em relação ao tamanho a maior parte obedece aos preceitos das práticas recomendadas, ou seja, possuem três membros participantes do comitê de auditoria. Contudo, as empresas apresentam práticas heterogêneas nessa característica. Existem tanto aquelas com apenas um ou dois membros como outras que possuem mais de seis membros. Em 2013 existiam 192 membros dos comitês de 59 empresas. Desses, 48 são engenheiros, 45 economistas, 41 administradores, 26 contadores e um auditor. De modo geral, conclui-se que a criação do comitê de auditoria ainda não é uma prática institucionalizada pelas empresas brasileiras e que se manifesta de formas distintas entre as organizações.

Palavras-chave: Comitê de auditoria. Tamanho. Independência. Expertise. 


\begin{abstract}
The study aimed to verify the characteristics of size, independence and expertise of the audit committees of companies listed on the BM\&FBovespa in 2010 to 2013. Among the 407 companies listed on the stock exchange, only 68 of them have audit committee trained in some period analyzed. The year 2013 had 59 companies with the audit committee, which is the largest number found, representing only $14.50 \%$ of the population. The main results showed that compared to most size complies with the precepts of best practices, have three participating members of the audit committee. However, companies have heterogeneous practices in this feature, existing both those with only one or two members as others that have more than six members. In 2013 there were 192 members of 59 committee's companies, and of these, 48 are engineers, 45 economists, 41 managers, 26 accountants and one auditor. Overall, it is concluded that the creation of the audit committee is not yet an established practice by Brazilian companies and that this manifests itself in different ways across organizations.
\end{abstract}

Keywords: Audit Committee. Size. Independence. Expertise.

\title{
1 INTRODUÇÃO
}

A governança corporativa é um sistema de monitoramento, direção e incentivos que relaciona todos os interesses dos agentes da organização. Separa propriedade e controle (Instituto Brasileiro de Governança Corporativa [IBGC], 2009a). Tem como objetivo criar um conjunto de mecanismos eficientes para assegurar o alinhamento do comportamento dos executivos com os interesses dos acionistas (Viana, 2010). A ação do Conselho de Administração na gestão das organizações é um desses mecanismos e um dos seus principais objetivos é garantir a transparência nas informações geradas e designar outros comitês auxiliares (Silveira, Barros, \& Famá, 2003).

De acordo com o IBGC (2009b), o Conselho de Administração pode estabelecer a criação de comitês para auxiliá-lo na execução de suas atividades. Um desses comitês subsidiados é o Comitê de Auditoria, que é responsável por fiscalizar e administrar questões referentes às demonstrações contábeis, finanças, controles internos e acompanhar trabalhos de auditoria interna e auditoria independente. A institucionalização do Comitê de Auditoria visa proporcionar maior transparência às informações e a assegurar uma prestação de contas legítima aos interessados e investidores (Oliveira \& Costa, 2005).

Baioco e Almeida (2017) avaliaram os efeitos do comitê de auditoria e do conselho fiscal com suas diferentes características na qualidade da informação contábil no Brasil. Os resultados evidenciaram que diferentes arranjos do conselho fiscal e a existência do comitê de auditoria impactam diferentemente as propriedades da informação contábil. Felo, Krishnamurthy e Solieri (2003) examinaram a relação entre as características do comitê de auditoria (composição - expertise e independência; e tamanho) com a qualidade das demonstrações financeiras. Os autores sugerem que as empresas poderiam melhorar a sua qualidade de apresentação das demonstrações financeiras e estruturar adequadamente os seus comitês de auditoria, reduzindo assim o seu custo de capital.

Desse modo, o comitê de auditoria constitui-se de um órgão descendente do conselho de administração, instituído para garantir a qualidade e a fidelidade das demonstrações e que possui características que colaboram para as boas práticas de governança corporativa, como o tamanho, independência e expertise. Assim, a questão que norteia esta pesquisa é: Quais são as características predominantes nos comitês de auditoria das empresas listadas na $B M \& F B o v e s p a$ ? Nesse sentido, o objetivo do estudo é verificar as características de tamanho, independência e expertise dos comitês de auditoria das empresas listadas na BM\&FBovespa.

O tamanho está relacionado à quantidade de membros que compõem o comitê, já a independência é determinada pela quantidade de membros que não possuem vínculo ou subordinação a outros níveis na mesma organização. Por sua vez, a expertise é uma característica que visa identificar os membros que possuem formação ou experiência 
profissional que os possibilitem analisar e aprovar as demonstrações contábeis e financeiras da organização de forma eficaz e íntegra (Teixeira, Camargo, \& Vicente, 2016; Felo et al., 2003).

Estudos sobre comitê de auditoria têm sido realizados em âmbito nacional e internacional. Tais estudos têm como foco de investigação a relação entre as características do comitê de auditoria com o gerenciamento de resultados (Cunha, Hillesheim, Faveri, \& Rodrigues Junior, 2014; Habbash, Sindezingue \& Salama, 2013; Klein, 2002) e com a qualidade da auditoria independente (Teixeira et al., 2016; Lary \& Taylor, 2012); a comparação das características propostas para o comitê de auditoria no código de governança corporativa do Brasil e de outros países (Beuren, Nass, Theiss, \& Cunha, 2013); a análise das características do comitê de auditoria na governança corporativa das companhias brasileiras de capital aberto (Oliveira \& Costa, 2005); a relação entre as características do comitê de auditoria (independência, expertise e frequência de reuniões) com o honorário de auditoria (Adelopo, Jallow, \& Scott, 2012); a relação entre as características da empresa, do comitê de auditoria e do auditor independente com o prazo de publicação das demonstrações financeiras (Cunha, Pletsch, \& Silva, 2015) e a relação entre as características do comitê de auditoria e o audit delay (Cunha, Lunelli, Santos Faveri \& Rodrigues Júnior, 2015).

Esta pesquisa concentra-se em diagnosticar as características dos comitês de auditoria. Esse diagnóstico é útil porque pode auxiliar as empresas na estruturação dos seus comitês de auditoria, uma vez que apresenta as principais características existentes e necessárias para garantir a eficácia desse mecanismo, que, por sua vez, contribui para a melhoria das boas práticas de governança corporativa. Outro ponto que justifica o trabalho é a contribuição para a tomada de decisão dos investidores, que podem conhecer mais profundamente os comitês de auditoria e entender suas principais características. A existência e empregabilidade dessas características influenciam na qualidade e transparência das demonstrações e pareceres gerados pelo comitê de auditoria. De acordo com Cunha, Sant'Ana, Theiss e Krespi (2013) ao apresentar as diretrizes atribuídas ao comitê de auditoria, associadas às características dos seus componentes, contribui-se para as organizações ao refletir maior qualidade das demonstrações contábeis e maior segurança aos acionistas e investidores.

\section{COMITÊ DE AUDITORIA}

A Governança Corporativa tem a finalidade de dirimir o conflito da agência, que surge quando há separação entre propriedade e controle (Viana, 2010). É o sistema pelo qual as organizações são conduzidas, monitoradas e estimuladas. Envolve os proprietários, o conselho de administração, a diretoria e os órgãos de controle (IBGC, 2009a). Para Viana (2010) e Silveira, Barros e Famá (2003), a governança corporativa norteia-se em criar um conjunto eficiente de mecanismos, tanto de incentivos quanto de monitoramento, a fim de assegurar que o comportamento dos executivos esteja sempre alinhado com o interesse dos acionistas. Dentre os mecanismos destaca-se a ação do Conselho de Administração e a transparência nas informações por meio da obrigatoriedade da publicação de informações sobre a companhia (Silveira et al., 2003).

De acordo com o IBGC (2009b), o Conselho de Administração pode instituir vários comitês para auxiliá-lo na execução de suas atividades, tomada de decisão e descentralização de alguns pontos da gestão. Dentre os comitês que podem ser formados, há o comitê de auditoria, responsável por fiscalizar as demonstrações contábeis, controles internos, área financeira, auditoria interna e auditoria independente. O Guia de Diretrizes de Governança Corporativa da BM\&FBovespa (2015), afirma que o comitê de auditoria é um mecanismo de Governança Corporativa, que tem por responsabilidade a gestão dos procedimentos internos, bem como assegurar que tais procedimentos sejam dignos e eficazes para a produção de relatórios financeiros de qualidade, objetivando a proteção dos acionistas e demais usuários da informação contábil.

A Lei Sarbanes-Oxley, em sua seção 301, estabelece que o comitê de auditoria deve ser composto por no mínimo três membros integrantes do conselho de administração. Igualmente, a Resolução n. 3.198/04 do Conselho Monetário Nacional [CMN] (2004) afirma que o comitê de auditoria deve ser formado por no mínimo três membros, com atividades 
indelegáveis que devem ser descritas no estatuto social da organização. A Comissão de Valores Mobiliários [CVM] (2002) recomenda ainda que o comitê de auditoria deve incluir pelo menos um conselheiro que represente os minoritários entre seus membros. Segundo Yang e Krishnan (2005) quanto maior o tamanho do Comitê de Auditoria, maior a variedade de conhecimentos existentes para o desempenho eficaz das atividades do comitê.

A Resolução n. 3.198/04, no art. 12, CMN (2004) estabelece que o mandato dos membros do comitê de auditoria deve ser no máximo de um período de cinco anos. Excetuamse as companhias de capital fechado que não necessitam de mandato fixo para os conselheiros do comitê; e que o integrante do comitê de auditoria somente pode voltar a integrar tal órgão na mesma instituição depois de decorridos, no mínimo, três anos do final do seu mandato. Yang e Krishman (2005) verificaram que os membros do comitê que possuem mais de um mandato ganham experiência e contribuem na redução do gerenciamento de resultados.

O comitê de auditoria deverá manter sua independência, a fim de não sofrer influência interna e isso refletir negativamente na efetividade da análise das demonstrações contábeis (Beuren et al., 2013). De acordo com o IBGC (2009b), os membros do comitê de auditoria devem ser independentes, ou pelo menos a maioria deles. Klein (2002) constatou que quanto maior o número de membros independentes de um comitê, melhor a qualidade da informação disponibilizada ao usuário.

O Código das Melhores Práticas de Governança Corporativa (IBGC, 2009b), em seu item 2.16, dispõe que a quantidade de conselheiros independentes dependerá do grau de maturidade da organização, do seu ciclo de vida e de suas características. O mesmo código recomenda que a maioria seja composta por independentes, contratados por meio de processos formais e com escopo de atuação e qualificação bem definido.

A Lei Sarbanes-Oxley define na Seção 301 que membro independente é aquele que não recebe, exceto por prestação de serviços no conselho, qualquer honorário de consultoria, assessoria ou outro tipo de compensação por parte da empresa, e não é pessoa afiliada dessa, nem de suas subsidiárias. Esse fato é ratificado pelo IBGC (2009a) no item 3.3 do Guia de Orientação para Melhores Práticas de Comitês de Auditoria, o qual menciona que para manter sua independência, os membros do comitê de auditoria não devem receber qualquer outro tipo de remuneração da organização ou de suas partes relacionadas que não seja aquela relativa à sua função de conselheiro e de integrante do comitê. A independência diz respeito à capacidade de exercer julgamentos e demonstra-se na forma como se desempenha a função (IBGC, 2009a).

Sua independência na análise e emissão do parecer do comitê de auditoria não é suficiente para assegurar que ocorra a transparência nas informações geradas. O comitê deve auxiliar o conselho de administração e a diretoria executiva na transparência, confiabilidade e efetividade do desempenho de suas funções e responsabilidades (Beuren et al. 2013).

A fim de manter a independência do comitê de auditoria, o conselho de administração deve fixar atribuições e responsabilidades para esse comitê, além de zelar para que essas designações sejam devidamente cumpridas. Essas atribuições devem estar expressas no estatuto ou no contrato social da organização (CMN, 2004).

A Figura 1, apresenta as atribuições básicas do comitê de auditoria contidas no texto internacional da Lei Sarbanes-Oxley e em âmbito nacional na Resolução 3.198/04 do CMN (2004):

\begin{tabular}{|c|c|}
\hline \multirow{5}{*}{ 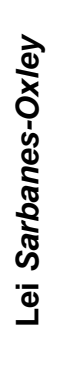 } & $\begin{array}{l}\text { - contratação, substituição e supervisão da auditoria independente ou externa, incluindo a resolução de } \\
\text { quaisquer conflitos entre a administração e os auditores independentes; }\end{array}$ \\
\hline & $\begin{array}{l}\text { - criação de procedimentos para receber, processar e lidar com reclamações e/ou denúncias contra a } \\
\text { administração, incluindo mecanismos de recebimento de denúncias anônimas e confidenciais por parte de } \\
\text { empregados; }\end{array}$ \\
\hline & $\begin{array}{l}\text { - interação e comunicação com os auditores externos e internos, conselho de administração, diretoria, } \\
\text { controllers, advogados, dentre outros agentes do processo de elaboração das demonstrações contábeis; }\end{array}$ \\
\hline & $\begin{array}{l}\text { - identificação de aspectos contábeis críticos e análise da adequada aplicação dos princípios contábeis } \\
\text { geralmente aceitos; }\end{array}$ \\
\hline & valiação dos controles internos e de riscos corporativos. \\
\hline
\end{tabular}


Figura 1 (continuação)

- estabelecer as regras operacionais para seu próprio funcionamento, as quais devem ser aprovadas pelo conselho de administração ou, na sua inexistência, pela diretoria da instituição formalizadas por escrito e colocadas à disposição dos respectivos acionistas ou cotistas;

- recomendar à administração da instituição, a entidade a ser contratada para prestação dos serviços de auditoria independente, bem como a substituição do prestador desses serviços, caso considere necessário;

- revisar, previamente à publicação, as demonstrações contábeis semestrais, inclusive notas explicativas, relatórios da administração e parecer do auditor independente;

- avaliar a efetividade das auditorias independente e interna, inclusive quanto à verificação do cumprimento de dispositivos legais e normativos aplicáveis à instituição, além de regulamentos e códigos internos;

- avaliar o cumprimento, pela administração da instituição, das recomendações feitas pelos auditores independentes ou internos;

- estabelecer e divulgar procedimentos para recepção e tratamento de informações acerca do descumprimento de dispositivos legais e normativos aplicáveis à instituição, além de regulamentos e códigos internos, inclusive com previsão de procedimentos específicos para proteção do prestador e da confidencialidade da informação;

- recomendar, à diretoria da instituição, correção ou aprimoramento de políticas, práticas e procedimentos identificados no âmbito de suas atribuições;

- reunir-se, no mínimo trimestralmente, com a diretoria da instituição, com a auditoria independente e com a auditoria interna para verificar o cumprimento de suas recomendações ou indagações, inclusive no que se refere ao planejamento dos respectivos trabalhos de auditoria, formalizando, em atas, os conteúdos de tais encontros;

- verificar, por ocasião das reuniões, o cumprimento de suas recomendações pela diretoria da instituição;

- reunir-se com o conselho fiscal e conselho de administração, por solicitação dos mesmos, para discutir acerca de políticas, práticas e procedimentos identificados no âmbito das suas respectivas competências;

- outras atribuições determinadas pelo Banco Central do Brasil.

Figura 1. Atribuições do comitê de auditoria

Fonte: Elaboração própria a partir dos preceitos da Lei Sarbanes-Oxley e da Resolução 3.198/04, CMN (2004).

Para Oliveira e Costa (2005), as atribuições apresentadas pelas duas legislações são semelhantes, porém a resolução brasileira contém maiores detalhes, como a participação em reuniões do conselho fiscal e a obrigatoriedade de elaboração de um relatório semestral. Sorrentino, Teixeira e Vicente (2016) investigaram o nível de adequação dos comitês de auditoria das empresas dos níveis diferenciados da BM\&FBovespa às regras da SOX, Bacen, Susep e IBGC. Para tanto, elaboraram um índice por meio da aplicação de um check-list baseado nas regras que atingem as empresas brasileiras. Os autores observaram que as empresas sujeitas às regras do BACEN e SUSEP formam o grupo com a maior adequação enquanto as empresas submetidas à SOX e as que são desobrigadas a constituir o comitê de auditoria apresentaram os índices mais baixos da amostra.

Em relação à expertise dos membros do comitê de auditoria, a Lei Sarbanes-Oxley, em sua seção 407, exige que o comitê de auditoria seja composto por pelo menos um especialista financeiro - Audit Committee Financial Expert (ACFE). Para a Securities and Exchange Commission - SEC (2003), um ACFE é definido como uma pessoa que tenha conhecimento acadêmico ou profissional em contabilidade, auditoria, controladoria, como, por exemplo, o CEO (Chief Executive Officer), o CFO (Chief Financial Officer) ou outros similares que possuírem qualificações e entendimentos em elaboração, auditoria, avaliação e análise das demonstrações contábeis, contabilização de provisões e reservas, compreensão dos controles internos e das funções do comitê de auditoria (Oliveira \& Costa, 2005).

Segundo a New York Stock Exchange - NYSE (2003), cada um dos membros do comitê de auditoria deve possuir conhecimentos de finanças, conforme o conselho de administração interpretar que seja necessário para o entendimento do negócio. Outro ponto considerado pela instituição é que pelo menos um dos membros do comitê deve ser perito em contabilidade ou administração financeira.

O Guia de Orientação para Melhores Práticas de Comitês de Auditoria do IBGC (2009a) apresenta que pelo menos um dos membros do comitê de auditoria deve possuir conhecimentos em contabilidade, auditoria e gestão financeira, além de reunir experiência em gestão de riscos de negócios de finanças e contabilidade. O item 2.30 do Código das Melhores Práticas de Governança Corporativa do IBGC (2009b) também trata da expertise dos membros do comitê ao apresentar que pelo menos um integrante deverá ter experiência comprovada na 
área Contábil ou de Auditoria. Desse modo, um comitê de auditoria eficiente começa na escolha dos seus integrantes que devem estar preparados para atender a essas qualificações (Oliveira \& Costa, 2005).

Em um estudo feito por Ika e Ghazali (2012) foi observado que a formação e experiência na área contábil, auditoria e finanças influencia na eficiência do comitê de auditoria. Em outra pesquisa, realizada por Dezoort, Hermanson e Houston (2003), foi ressaltado que comitês de auditoria que possuem maior experiência oferecem melhores resultados no momento de supervisionar os processos, a fim de garantir a integridade dos relatórios gerados. Evidenciam, assim, a importância dos membros do comitê de possuírem experiência financeira (Cunha, Pletsch, \& Silva, 2015). Nota-se, portanto, que a expertise não se refere apenas à formação acadêmica, mas também à experiência profissional do membro.

Felo et al., (2003) evidenciaram que após o controle do tamanho da empresa, composição do conselho, compromisso da administração com a transparência (a existência de um programa de ética) e a apropriação institucional, o percentual de membros do comitê de auditoria com experiência em contabilidade ou gestão financeira está positivamente relacionado à qualidade do relatório financeiro. Observaram ainda uma relação positiva entre o tamanho do comitê de auditoria e a qualidade de relatórios financeiros. No entanto, constataram que a independência do comitê de auditoria não está relacionada à qualidade do relatório financeiro. Os resultados da pesquisa de Felo et al., (2003) sugerem que exigir maior expertise em comitês de auditoria ao invés de simplesmente exigir um especialista no comitê de auditoria pode ser benéfico para os investidores.

A partir do exposto, denota-se que as principais características de um comitê de auditoria norteiam-se sobre o seu tamanho, que trata da quantidade de membros que o compõe; independência, ao ser composto por membros sem vínculo ou subordinação a outros níveis da organização e expertise, que abarca sobre a formação acadêmica e a experiência profissional, necessária para cumprir com credibilidade as funções determinadas pelos membros do comitê de auditoria. Todas essas características contribuem para melhorar a qualidade e transparência das informações geradas, o que aumenta a confiabilidade dos investidores e aprimora o nível de governança corporativa adotado pela organização.

\section{MÉTODOS E PROCEDIMENTOS DA PESQUISA}

Estudo de natureza descritiva foi realizado por meio de pesquisa documental e com abordagem quantitativa.

\subsection{População e amostra}

A partir do sítio da BM\&FBovespa (www.bmfbovespa.com.br) pesquisou-se todas as empresas listadas de acordo com o seu nível de governança corporativa. Inicialmente, a coleta de dados resultou em 739 empresas. Essa é a constituição da população da pesquisa. Dessa população, foram excluídas 332 empresas do setor financeiro, visto que apresentam peculiaridades que não se aplicam a esta pesquisa, restando 407 empresas.

O procedimento subsequente foi verificar quais empresas possuíam comitê de auditoria entre os anos de 2010 e 2013, o que resultou numa amostra de 68 empresas, conforme evidenciado na Tabela 1. É oportuno destacar que o critério de seleção da amostra levou em consideração que ao menos, em algum período, as empresas deveriam possuir comitê de auditoria. Dessa forma, fazem parte da amostra empresas que passaram a ter comitê de auditoria apenas em 2013, assim como empresas que possuíam comitê em 2010 e o eliminaram em períodos subsequentes.

Tabela 1

Número de empresas consideradas para a análise dos dados

\begin{tabular}{l|c|c|c|c|c}
\hline Setor Econômico & $\begin{array}{c}\text { Quant. } \\
\text { empresas }\end{array}$ & $\begin{array}{c}\text { Sem comitê } \\
\text { de auditoria }\end{array}$ & $\begin{array}{c}\% \text { de } \\
\text { participação }\end{array}$ & $\begin{array}{c}\text { Com comitê } \\
\text { de auditoria }\end{array}$ & $\begin{array}{c}\% \text { de } \\
\text { participação }\end{array}$ \\
\hline Bens Industriais & 36 & 34 & $94,44 \%$ & 2 & $5,56 \%$ \\
\hline
\end{tabular}


Tabela 1 (continuação)

\begin{tabular}{l|c|c|c|c|c}
\hline Setor Econômico & $\begin{array}{c}\text { Quant. } \\
\text { empresas }\end{array}$ & $\begin{array}{c}\text { Sem comitê } \\
\text { de auditoria }\end{array}$ & $\begin{array}{c}\text { \% de } \\
\text { participação }\end{array}$ & $\begin{array}{c}\text { Com comitê } \\
\text { de auditoria }\end{array}$ & $\begin{array}{c}\% \text { de } \\
\text { participação }\end{array}$ \\
\hline Construção e Transporte & 71 & 62 & $87,32 \%$ & 9 & $12,68 \%$ \\
Consumo Cíclico & 74 & 63 & $85,14 \%$ & 11 & $14,86 \%$ \\
Consumo não Cíclico & 59 & 48 & $81,36 \%$ & 11 & $18,64 \%$ \\
Materiais Básicos & 42 & 33 & $78,57 \%$ & 9 & $21,43 \%$ \\
Petróleo, Gás e Biocombustíveis & 12 & 8 & $66,67 \%$ & 4 & $33,33 \%$ \\
Tecnologia da Informação & 25 & 21 & $84,00 \%$ & 4 & $16,00 \%$ \\
Telecomunicações & 13 & 9 & $69,23 \%$ & 4 & $30,77 \%$ \\
Utilidade Pública & 75 & 61 & $81,33 \%$ & 14 & $18,67 \%$ \\
TOTAL (sem considerar setor financeiro) & $\mathbf{4 0 7}$ & 339 & $83,29 \%$ & $\mathbf{6 8}$ & $16,71 \%$ \\
\hline
\end{tabular}

Nota. Fonte: Dados da pesquisa.

A maioria das empresas está concentrada nos setores de Utilidade Pública com 75 empresas, Consumo Cíclico com 74 empresas e Construção e Transporte com 74 empresas. Porém, ao observar o percentual de participação das empresas com comitê de auditoria, temse que o setor de Petróleo, Gás e Biocombustíveis e Telecomunicações são os mais representativos, com 33,33\% e 30,77\%, respectivamente, ou seja, esses setores são os que mais possuem representatividade em termos percentuais de constituição de comitê de auditoria. Estão sujeitos a regulamentações específicas, o que pode contribuir para a constituição dos comitês de auditoria. De modo geral, observa-se que a presença de comitê de auditoria ainda é embrionária nas empresas listadas na BM\&FBovespa. Segundo o IBGC (2009a), recomenda-se a instituição do comitê de auditoria para analisar as demonstrações financeiras, promover a supervisão da área financeira, garantir o desenvolvimento de controles internos confiáveis, avalizar que a auditoria interna desempenhe o seu papel e que os auditores independentes avaliem as práticas da diretoria e da auditoria interna.

\subsection{Variáveis analisadas}

As características dos comitês de auditoria analisadas foram mensuradas utilizando-se as variáveis expostas na Figura 2 a seguir.

\begin{tabular}{|c|c|c|}
\hline Características & Forma de apuração e mensuração & Autores \\
\hline Tamanho & $\begin{array}{l}\text { Quantidade de membros que compõem o } \\
\text { comitê de auditoria. }\end{array}$ & $\begin{array}{l}\text { CVM (2002); Resolução } 3.198 \text { (2004); Yang } \\
\text { e Krishnan (2005) }\end{array}$ \\
\hline Independência & $\begin{array}{l}\text { Quantidade de membros independentes. } \\
\text { A independência foi considerada quando o } \\
\text { membro não era encontrado em outro comitê } \\
\text { ou diretoria da organização. Esses dados } \\
\text { foram pesquisados no Formulário de } \\
\text { Referência (item } 12.7-\text { Composição dos } \\
\text { comitês e } 1.1 \text { - Declaração e identificação dos } \\
\text { responsáveis pelo formulário). }\end{array}$ & $\begin{array}{l}\text { Beuren et al. (2013); CVM (2002); IBGC } \\
\text { (2009a). }\end{array}$ \\
\hline Expertise & $\begin{array}{l}\text { Quantidade de membros com conhecimento } \\
\text { em contabilidade, auditoria e finanças. } \\
\text { O conhecimento foi considerado quando a } \\
\text { Profissão encontrada no Formulário de } \\
\text { Referência (item } 12.7 \text { - Composição dos } \\
\text { comitês) dos membros do comitê de auditoria } \\
\text { era igual a: Auditor, Contador e/ou } \\
\text { Economista/Finanças. }\end{array}$ & $\begin{array}{l}\text { Dezoort, Hermanson e Houstn (2003); IBGC } \\
\text { (2009a); Ika e Ghazali (2012); NYSE (2003); } \\
\text { Cunha, Pletsch, \& Silva, 2015). }\end{array}$ \\
\hline
\end{tabular}

Figura 2. Características analisadas

Fonte: Elaboração própria.

Após a delimitação das variáveis selecionadas para o estudo e a forma de mensurá-las, iniciou-se a coleta e a análise dos dados. 


\subsection{Procedimentos de coleta e análise dos dados}

Utilizou-se o sítio da BM\&FBovespa para pesquisar as empresas listadas entre os anos de 2010 e 2013 de acordo com seu setor de atuação e o seu nível de governança corporativa. Os dados relacionados às características do comitê de auditoria foram coletados no sítio da BM\&FBovespa, mais especificamente no Formulário de Referência, subseção 12.7 (composição dos comitês), que descreve a composição de todos os comitês ligados ao conselho de administração. Nesse formulário pesquisaram-se as informações de tamanho, independência e expertise do comitê de auditoria.

Os dados quanto à caracterização das empresas da amostra foram retirados das páginas institucionais das próprias organizações, bem como da publicação no sítio do Valor Econômico ${ }^{\circledR}$ da Revista Valor 1000 no ano de 2013. Para análise dos dados, utilizou-se a estatística descritiva, em que foram determinados o mínimo e máximo, médias, moda, desvio padrão e coeficiente de variação das variáveis: Tamanho, Independência e Expertise em cada período.

\section{DESCRIÇÃO E ANÁLISE DOS DADOS}

Nesta seção, primeiramente apresenta-se o perfil das empresas que possuíam comitê de auditoria em qualquer um dos anos investigados, ou seja, entre 2010 e 2013. Em seguida, apresentam-se as características dos comitês de auditoria em termos de tamanho, independência e expertise. Por fim, com o intuito de identificar alguma tendência, por meio da estatística descritiva, analisam-se as características ao longo do período analisado.

\subsection{Perfil das empresas}

Foram coletados dados de 68 empresas listadas na BM\&FBovespa e que possuíam comitê de auditoria entre os anos de 2010 e 2013. O perfil dessas empresas foi delimitado com base nos setores, nível de governança corporativa, número de funcionários e lucro líquido do ano de 2013, cujas informações estão sintetizadas na Tabela 2.

Tabela 2

Perfil das empresas analisadas

\begin{tabular}{l|c|c|l|c|c}
\hline Setor & Quantidade & $\%$ & Quantidade de funcionários & Quantidade & $\%$ \\
\hline Bens Industriais & 2 & $2,94 \%$ & De 0 a 500 & 11 & $16,18 \%$ \\
Construção e Transporte & 9 & $13,24 \%$ & De 501 a 1.000 & 4 & $5,88 \%$ \\
Consumo Cíclico & 11 & $16,18 \%$ & De 1.001 a 1.500 & 3 & $4,41 \%$ \\
Consumo não Cíclico & 11 & $16,18 \%$ & De 1.501 a 3.000 & 7 & $10,29 \%$ \\
Materiais Básicos & 9 & $13,24 \%$ & De 3.001 a 6.000 & 9 & $13,24 \%$ \\
Petróleo, Gás e Biocombustíveis & 4 & $5,88 \%$ & De 6.001 a 16.000 & 21 & $30,88 \%$ \\
Tecnologia da Informação & 4 & $5,88 \%$ & De 16.001 a 40.000 & 8 & $11,76 \%$ \\
Telecomunicações & 4 & $5,88 \%$ & De 40.000 a 100.000 & 3 & $4,41 \%$ \\
Utilidade Pública & 14 & $20,59 \%$ & Acima de 100.001 & 2 & $2,94 \%$ \\
\hline Total & $\mathbf{6 8}$ & $\mathbf{1 0 0 \%}$ & Total & $\mathbf{6 8}$ & $\mathbf{1 0 0 \%}$ \\
\hline Nível de Governança & Quantidade & $\%$ & Resultado líquido (milhões) & Quantidade & $\%$ \\
\hline Balcão Organizado Tradicional & 1 & $1,47 \%$ & Prejuízo & 14 & $20,59 \%$ \\
BDR Nível 3 & 2 & $2,94 \%$ & De 01 a 250 & 25 & $36,76 \%$ \\
Bovespa Mais & 2 & $2,94 \%$ & De 251 a 500 & 9 & $13,24 \%$ \\
Nível 1 de Governança Corporativa & 4 & $5,88 \%$ & De 501 a 750 & 7 & $10,29 \%$ \\
Nível 2 de Governança Corporativa & 4 & $5,88 \%$ & De 751 a 1.000 & 4 & $5,88 \%$ \\
Novo Mercado & 44 & $64,71 \%$ & De 1.001 a 2.000 & 7 & $10,29 \%$ \\
\hline & & & Continua
\end{tabular}


Tabela 2 (continuação)

\begin{tabular}{l|c|c|l|c|c}
\hline Nível de Governança & Quantidade & $\%$ & Resultado líquido (milhões) & Quantidade & $\%$ \\
\hline Tradicional - Bovespa & 11 & $16,18 \%$ & Acima de 2.001 & 2 & $2,94 \%$ \\
\hline Total & $\mathbf{6 8}$ & $\mathbf{1 0 0} \%$ & Total & $\mathbf{6 8}$ & $\mathbf{1 0 0 \%}$ \\
\hline
\end{tabular}

Nota. Fonte: Dados da pesquisa.

Observa-se que o setor com maior representatividade é o de Utilidade Pública. Nesse grupo reúnem-se todas as empresas de capital aberto que possuem atividades relacionadas ao fornecimento de serviços de necessidade básica para a população em geral: energia elétrica, gás natural e abastecimento de água, com $20,59 \%$ das empresas analisadas, seguidos pelos setores de Consumo Cíclico, representando o comércio atacadista e varejista, e Consumo não Cíclico, representando todas as empresas que possuem como atividade a agricultura, pecuária, produção florestal, caça, pesca e transformação industrial alimentícia e têxtil, com 16,18\%, cada. O setor de Bens Industriais, que engloba todas as empresas de produção industrial de metais, maquinários, madeira, papel e químicos, é o que possui menor índice de empresas com comitê de auditoria nos anos pesquisados, com 2,94\%.

Ao analisar por nível de governança corporativa, tem-se que $64,7 \%$ estão enquadradas no nível de Novo Mercado. Segundo a BM\&FBovespa (2014), esse é o grupo que conduz as empresas ao mais elevado padrão de Governança Corporativa, o que explica a preocupação em manter comitês de auditoria em suas estruturas organizacionais. A menor representatividade nesse indicador está no nível de Balcão Organizado Tradicional, com 1,47\% das empresas analisadas. Nesse grupo enquadram-se as empresas menores que não possuem todas as exigências para enquadramento em outros níveis. De acordo com informações do sítio da BM\&FBovespa (2014), as regras aplicáveis aos segmentos das empresas listadas definem não somente o nível de governança, como também atraem os investidores ao assegurar direitos e garantias aos acionistas, assim como há redução do risco com a divulgação de informações mais completas para controladores, gestores da companhia e participantes do mercado. Todavia, Sorrentino, Teixeira e Vicente $(2016$, p. 241) não encontraram "relação entre os níveis diferenciados de governança corporativa e o índice de adequação dos comitês, ou seja, possuir classificação no novo mercado não garante uma boa adequação às normas referentes ao comitê de auditoria".

Ao avaliar a distribuição das empresas pelo número de funcionários, verifica-se que a maior concentração está nas faixas que possuem entre 6.001 e 16.000 e 0 a 500 funcionários em seu quadro produtivo. E apenas 02 empresas da amostra possuíam mais de 100.000 colaboradores no ano de 2013. Essas empresas pertencem ao setor de consumo não cíclico, mais precisamente à atividade de transformação industrial alimentícia, e o lucro líquido de ambas em 2013 foi superior a R\$ 1 bilhão de reais. Ainda em relação ao número de funcionários, o menor número encontrado foi de 12 numa empresa do setor de materiais básicos e o maior foi de 216.693 funcionários.

Considerando o resultado apresentado pelas empresas em 2013, a maior parcela concentra-se nas organizações que obtiveram de 01 a 250 milhões de lucro líquido $(36,76 \%)$, seguida por $20,59 \%$ que representam as empresas que mostraram resultado negativo no período. O maior prejuízo foi de $\mathrm{R} \$ 17,4$ bilhões de reais de uma empresa do setor de petróleo, gás e biocombustíveis ao passo que o maior resultado encontrado foi $R \$ 23$ bilhões de reais do mesmo setor, o que evidencia a heterogeneidade da amostra analisada.

Denota-se, de modo geral, que as empresas com comitê de auditoria concentram-se no setor de utilidade pública; quanto ao nível de governança corporativa a maioria pertence ao Novo Mercado. Possuem entre 6.001 a 16.000 funcionários e a maior parte apresentou um lucro líquido em 2013 na faixa de até 250 milhões de reais.

\subsection{Características dos comitês de auditoria}

No que concerne às características do comitê de auditoria, inicialmente foi realizada uma análise geral dos dados levantados na pesquisa. 


\section{a) Tamanho do comitê de auditoria}

$\mathrm{Na}$ Tabela 3 evidencia-se o número de membros do comitê de auditoria e a respectiva quantidade de empresas no período de 2010 a 2013.

Tabela 3

Números de membros do comitê de auditoria e a respectiva quantidade de empresas

\begin{tabular}{l|c|c|c|c|c|c|c|c}
\hline \multicolumn{2}{c|}{$\begin{array}{c}\text { Números de } \\
\text { membros do } \\
\text { comitê de } \\
\text { auditoria }\end{array}$} & \multicolumn{2}{|c|}{$\mathbf{2 0 1 0}$} & \multicolumn{2}{c|}{$\mathbf{2 0 1 1}$} & \multicolumn{2}{c|}{$\mathbf{2 0 1 2}$} \\
\cline { 2 - 9 } & Qtde de & $\%$ & $\begin{array}{c}\text { Qtde de } \\
\text { Empresas }\end{array}$ & $\%$ & $\begin{array}{c}\text { Qtde de } \\
\text { Empresas }\end{array}$ & $\%$ & $\begin{array}{c}\text { Qtde de } \\
\text { Empresas }\end{array}$ & $\%$ \\
\hline Sem comitê & 12 & $17,65 \%$ & 12 & $17,65 \%$ & 10 & $14,71 \%$ & 9 & $13,24 \%$ \\
1 membro & 0 & $0,00 \%$ & 1 & $1,47 \%$ & 2 & $2,94 \%$ & 1 & $1,47 \%$ \\
2 membros & 10 & $14,71 \%$ & 9 & $13,24 \%$ & 9 & $13,24 \%$ & 11 & $16,18 \%$ \\
3 membros & 29 & $42,65 \%$ & 29 & $42,65 \%$ & 34 & $50,00 \%$ & 31 & $45,59 \%$ \\
4 membros & 9 & $13,24 \%$ & 10 & $14,71 \%$ & 7 & $10,29 \%$ & 9 & $13,24 \%$ \\
5 membros & 3 & $4,41 \%$ & 3 & $4,41 \%$ & 3 & $4,41 \%$ & 4 & $5,88 \%$ \\
6 membros & 4 & $5,88 \%$ & 3 & $4,41 \%$ & 2 & $2,94 \%$ & 2 & $2,94 \%$ \\
7 membros & 0 & $0,00 \%$ & 0 & $0,00 \%$ & 0 & $0,00 \%$ & 0 & $0,00 \%$ \\
8 membros & 0 & $0,00 \%$ & 1 & $1,47 \%$ & 1 & $1,47 \%$ & 1 & $1,47 \%$ \\
9 membros & 1 & $1,47 \%$ & 0 & $0,00 \%$ & 0 & $0,00 \%$ & 0 & $0,00 \%$ \\
TOTAL & $\mathbf{6 8}$ & $\mathbf{1 0 0} \%$ & $\mathbf{6 8}$ & $\mathbf{1 0 0} \%$ & $\mathbf{6 8}$ & $\mathbf{1 0 0} \%$ & $\mathbf{6 8}$ & $\mathbf{1 0 0 \%}$ \\
\hline
\end{tabular}

Nota. Fonte: Dados da pesquisa.

Quanto ao número de membros que compõem o comitê de auditoria percebe-se que em todos os anos que a maioria das empresas mantinha entre 03 a 04 membros, com uma representatividade entre $55,89 \%$ e $60,29 \%$ no período. As empresas que apresentaram mais de 05 membros em sua composição correspondem a uma média de 10,29\% nos anos pesquisados. Também foram identificadas 12 empresas que não possuíam comitê de auditoria nos anos de 2010 e 2011, número que reduziu em 2012 para 10 empresas e em 2013 para 09. Houve empresas que no decorrer do período instituíram comitê de auditoria em seu quadro organizacional, fato esse que pode confirmar a hipótese das empresas estarem mais preocupadas com a transparência e confiabilidade das informações geradas. Em contrapartida, houve 09 empresas que possuíam o comitê de auditoria instituído em pelo menos um dos primeiros anos analisados, chegando em 2013 sem esse órgão estabelecido.

Ao analisar a disposição da Lei Sarbanes-Oxley e da Resolução n. 3.198/04, que estabelecem que o comitê de auditoria deve ser composto por no mínimo 03 integrantes, verifica-se que dentre as empresas com comitê instituído, há aquelas que apresentam membros numa quantidade inferior à prática recomendada. Nota-se que em 2010 há 56 empresas com comitê de auditoria constituído, sendo que 10 possuíam apenas dois membros. Tal panorama não sofreu alterações nos períodos subsequentes. Em 2013, por exemplo, existiam 59 empresas com comitê de auditoria. Dessas, 11 continham apenas dois membros e uma delas um único membro. Sendo assim, essas empresas mantiveram um comitê de auditoria com um número inferior de membros preconizados pela legislação. Observa-se ainda que apenas uma única empresa possui oito e/ou nove membros no seu comitê de auditoria. Essa empresa pertence ao setor de telecomunicação, do Novo Mercado (nível de governança) e possui 10.300 empregados.

\section{b) Independência do comitê de auditoria}

Na Tabela 4 demonstra-se o número de membros independentes no comitê de auditoria e a respectiva quantidade de empresas. 
Tabela 4

Números de membros do comitê de auditoria e a respectiva quantidade de empresas

\begin{tabular}{c|c|c|c|c|c|c|c|c}
\hline $\begin{array}{c}\text { Membros } \\
\text { independentes no } \\
\text { comitê de } \\
\text { auditoria }\end{array}$ & \multicolumn{2}{|c|}{$\mathbf{2 0 1 0}$} & \multicolumn{2}{c|}{$\mathbf{2 0 1 1}$} & \multicolumn{2}{c|}{$\mathbf{2 0 1 2}$} & \multicolumn{3}{c}{$\mathbf{2 0 1 3}$} \\
\cline { 2 - 9 } & $\begin{array}{c}\text { Qtde de } \\
\text { Empresas }\end{array}$ & $\%$ & $\begin{array}{c}\text { Qtde de } \\
\text { Empresas }\end{array}$ & $\%$ & $\begin{array}{c}\text { Qtde de } \\
\text { Empresas }\end{array}$ & $\%$ & $\begin{array}{c}\text { Qtde de } \\
\text { Empresas }\end{array}$ & $\%$ \\
\hline Nenhum membro & 12 & $17,65 \%$ & 12 & $17,65 \%$ & 10 & $14,71 \%$ & 9 & $13,24 \%$ \\
1 membro & 0 & $0,00 \%$ & 1 & $1,47 \%$ & 2 & $2,94 \%$ & 1 & $1,47 \%$ \\
2 membros & 15 & $22,06 \%$ & 14 & $20,59 \%$ & 14 & $20,59 \%$ & 14 & $20,59 \%$ \\
3 membros & 29 & $42,65 \%$ & 28 & $41,18 \%$ & 33 & $48,53 \%$ & 32 & $47,06 \%$ \\
4 membros & 7 & $10,29 \%$ & 8 & $11,76 \%$ & 5 & $7,35 \%$ & 7 & $10,29 \%$ \\
5 membros & 3 & $4,41 \%$ & 2 & $2,94 \%$ & 1 & $1,47 \%$ & 2 & $2,94 \%$ \\
6 membros & 1 & $1,47 \%$ & 2 & $2,94 \%$ & 2 & $2,94 \%$ & 2 & $2,94 \%$ \\
7 membros & 1 & $1,47 \%$ & 1 & $1,47 \%$ & 1 & $1,47 \%$ & 0 & $0,00 \%$ \\
8 membros & 0 & $0,00 \%$ & 0 & $0,00 \%$ & 0 & $0,00 \%$ & 1 & $1,47 \%$ \\
\hline
\end{tabular}

Nota. Fonte: Dados da pesquisa.

Nota-se que a quantidade de membros independentes também concentra-se na faixa de 03 membros, com 44,85\%, seguida pela faixa de 02 membros, com 20,96\%, atendendo às determinações da CVM (2002) e IBGC (2009a) de manter a maioria dos seus membros independentes para que não haja influência na capacidade de ser imparcial na análise das demonstrações contábeis e financeiras e pareceres sobre a gestão da organização. Os dados apresentados como "nenhum membro" representam o mesmo número de empresas que não possuíam o comitê de auditoria, conforme evidenciado na Tabela 3, o que representa que todos os comitês de auditoria encontrados nos anos pesquisados contavam com pelo menos 01 membro independente, conforme recomendação do IBGC. Esse fato foi corroborado pela pesquisa de Cunha et al. (2014), na qual identificaram os reflexos das características do comitê de auditoria e o gerenciamento de resultados. Neste estudo, os autores verificaram que nos anos de 2010 e 2011 mais de $50 \%$ das empresas pesquisadas possuíam Comitês de Auditoria compostos por maioria de membros independentes.

\section{c) Expertise do comitê de auditoria}

A fim de caracterizar os membros do comitê de auditoria pela sua qualificação profissional, definindo a sua expertise, elaborou-se a Tabela 5 apresentada na sequência.

Tabela 5

Qualificação dos membros do comitê de auditoria

\begin{tabular}{lcc|cc|cc|cc}
\hline \multirow{2}{*}{ Qualificação } & \multicolumn{2}{c|}{2010} & \multicolumn{2}{c|}{$\mathbf{2 0 1 1}$} & \multicolumn{2}{c}{$\mathbf{2 0 1 2}$} & \multicolumn{2}{c}{$\mathbf{2 0 1 3}$} \\
& Quant. & $\%$ & Quant. & $\%$ & Quant. & $\%$ & Quant. & $\%$ \\
\hline Administrador & 37 & $19,37 \%$ & 39 & $20,86 \%$ & 33 & $17,84 \%$ & 41 & $21,35 \%$ \\
Advogado & 16 & $8,38 \%$ & 14 & $7,49 \%$ & 15 & $8,11 \%$ & 16 & $8,33 \%$ \\
Analista de sistemas & 0 & $0,00 \%$ & 1 & $0,53 \%$ & 0 & $0,00 \%$ & 1 & $0,52 \%$ \\
Arquiteto & 0 & $0,00 \%$ & 1 & $0,53 \%$ & 1 & $0,54 \%$ & 1 & $0,52 \%$ \\
Auditor & 0 & $0,00 \%$ & 0 & $0,00 \%$ & 0 & $0,00 \%$ & 1 & $0,52 \%$ \\
Bancário & 3 & $1,57 \%$ & 3 & $1,60 \%$ & 2 & $1,08 \%$ & 3 & $1,56 \%$ \\
Consultor & 0 & $0,00 \%$ & 2 & $1,07 \%$ & 1 & $0,54 \%$ & 1 & $0,52 \%$ \\
Contador & 26 & $13,61 \%$ & 23 & $11,76 \%$ & 24 & $14,05 \%$ & 26 & $13,54 \%$ \\
Desembargador de justiça & 1 & $0,52 \%$ & 0 & $0,00 \%$ & 0 & $0,00 \%$ & 0 & $0,00 \%$ \\
Economista/Finanças & 46 & $24,08 \%$ & 46 & $24,60 \%$ & 45 & $24,86 \%$ & 45 & $23,44 \%$ \\
\hline
\end{tabular}


Tabela 5 (continuação)

\begin{tabular}{lcc|cc|cc|cc}
\hline \multirow{2}{*}{ Qualificação } & \multicolumn{2}{c}{2010} & \multicolumn{2}{c|}{$\mathbf{2 0 1 1}$} & \multicolumn{2}{c}{$\mathbf{2 0 1 2} \mathbf{2 0 1 3}$} & \multicolumn{2}{c}{ Q12 } \\
& Quant. & $\%$ & Quant. & $\%$ & Quant. & $\%$ & Quant. & $\%$ \\
\hline Engenheiro & 51 & $26,70 \%$ & 50 & $26,74 \%$ & 51 & $27,57 \%$ & 48 & $25,00 \%$ \\
Físico & 0 & $0,00 \%$ & 1 & $0,53 \%$ & 1 & $0,54 \%$ & 1 & $0,52 \%$ \\
Funcionário público & 0 & $0,00 \%$ & 0 & $0,00 \%$ & 0 & $0,00 \%$ & 1 & $0,52 \%$ \\
Estatístico & 3 & $1,57 \%$ & 0 & $0,00 \%$ & 0 & $0,00 \%$ & 0 & $0,00 \%$ \\
Investidor & 1 & $0,52 \%$ & 1 & $0,53 \%$ & 0 & $0,00 \%$ & 0 & $0,00 \%$ \\
Jornalista & 1 & $0,52 \%$ & 1 & $0,53 \%$ & 1 & $0,54 \%$ & 1 & $0,52 \%$ \\
Matemático & 0 & $0,00 \%$ & 0 & $0,00 \%$ & 1 & $0,54 \%$ & 0 & $0,00 \%$ \\
Médico & 1 & $0,52 \%$ & 1 & $0,53 \%$ & 2 & $1,08 \%$ & 1 & $0,52 \%$ \\
Militar & 1 & $0,52 \%$ & 1 & $0,53 \%$ & 1 & $0,54 \%$ & 1 & $0,52 \%$ \\
Professor & 4 & $2,09 \%$ & 4 & $2,14 \%$ & 4 & $2,16 \%$ & 4 & $2,08 \%$ \\
\hline Total & $\mathbf{1 9 1}$ & $\mathbf{1 0 0} \%$ & $\mathbf{1 8 7}$ & $\mathbf{1 0 0} \%$ & $\mathbf{1 8 5}$ & $\mathbf{1 0 0} \%$ & $\mathbf{1 9 2}$ & $\mathbf{1 0 0} \%$ \\
\hline
\end{tabular}

Nota. Fonte: Dados da pesquisa.

Observa-se na Tabela 5 que a quantidade de membros presentes nos comitês de auditoria das empresas não sofreu alterações significativas ao longo do período. Sua quantidade ficou entre 185 a 192 membros. Nota-se que a maior concentração possui formação em engenharia, com uma média de 50 membros, economia/finanças, com aproximadamente 45 membros, por ano e administração, com uma média de 37 membros. 0 maior número de membros foi identificado no ano de 2013, com a participação de 192 membros nos comitês de auditoria das 59 empresas que possuíam comitês instituídos nesse período.

De acordo com Dezoort, Hermanson e Houstn (2003), IBGC (2009a), Ika e Ghazali (2012), NYSE (2003) e Cunha, Pletsch, e Silva (2015), a expertise necessária para manter o discernimento no comitê de auditoria deve ser advinda de conhecimentos em contabilidade, finanças ou auditoria. Pelo menos um dos membros do comitê deve ser especialista em uma dessas áreas. Em se tratando de conhecimentos em contabilidade, nota-se que em todos os anos encontram-se membros com essa especialidade. Em 2010, representavam 14,29\% do total de membros encontrados. Essa participação foi reduzida para $13,56 \%$ dos casos em 2013, porém a quantidade de profissionais dessa área de atuação não se alterou. Quanto aos conhecimentos de finanças, consideraram-se os membros com profissão relacionada à economia. Em 2010, esses profissionais representavam $24,08 \%$ do total de membros, passando para 23,44\% em 2013. Em contrapartida, tem-se que apenas em 2013 encontrou-se 01 profissional com conhecimento em auditoria.

Percebe-se, portanto, que, em 2010, apenas $37,7 \%$ dos membros do comitê de auditoria possuíam a expertise mencionada como necessária para garantir a qualidade e eficiência do comitê. Em 2011, eram 36,9\%, passando para 37,3\% em 2012 e aumentando em 2013, quando 72 dos 192 membros (37,5\%) eram experts em alguma dessas áreas.

A expertise pode ser obtida por meio de experiência profissional ou formação acadêmica, porém nesta pesquisa foram consideradas apenas as informações de profissão descritas no Formulário de Referência de cada um dos membros do comitê de auditoria. Sendo assim, pode existir profissionais com a expertise necessária e que não estão contemplados nos dados coletados desta pesquisa.

Contudo, conforme visto no referencial teórico deste trabalho, é oportuno destacar que a função do comitê de auditoria é garantir a transparência e a probidade das informações contábeis e financeiras que serão utilizadas como ferramenta de gestão para os investidores. Deste modo, é importante que as empresas tenham ao menos um membro constituído com formação e/ou experiência em contabilidade. 


\subsection{Estatística descritiva das características dos comitês de auditoria entre 2010 e 2013}

A estatística descritiva (mínimo, máximo, média, mediana, moda, desvio padrão e coeficiente de variação) foi aplicada nas variáveis tamanho, independência e expertise com o intuito de analisar tendências dos comitês de auditoria das empresas investigadas ao longo do tempo, cujos resultados são sintetizados na Tabela 6. Esses dados referem-se às empresas que efetivamente possuem comitê de auditoria formalmente constituído, ou seja, 56 empresas em 2010 e 2011, 58 empresas em 2012 e 59 empresas em 2013.

Tabela 6

Estatística descritiva aplicada nas variáveis

\begin{tabular}{|c|c|c|c|c|c|c|c|}
\hline \multicolumn{8}{|c|}{2010} \\
\hline Variável & Mínimo & Máximo & Média & Mediana & Moda & Desvio Padrão & $\begin{array}{l}\text { Coeficiente de } \\
\text { Variação }\end{array}$ \\
\hline Tamanho & 2 & 9 & 3,41 & 3,00 & 3,00 & 1,30 & $38,2 \%$ \\
\hline Independência & 2 & 7 & 3,09 & 3,00 & 3,00 & 1,03 & $33,4 \%$ \\
\hline Expertise & 0 & 6 & 1,25 & 1,00 & 1,00 & 1,12 & $89,3 \%$ \\
\hline \multicolumn{8}{|c|}{2011} \\
\hline Variável & Mínimo & Máximo & Média & Mediana & Moda & Desvio Padrão & $\begin{array}{l}\text { Coeficiente de } \\
\text { Variação }\end{array}$ \\
\hline Tamanho & 1 & 8 & 3,34 & 3,00 & 3,00 & 1,21 & $36,2 \%$ \\
\hline Independência & 1 & 7 & 3,11 & 3,00 & 3,00 & 1,11 & $35,6 \%$ \\
\hline Expertise & 0 & 4 & 1,23 & 1,00 & 1,00 & 1,04 & $84,8 \%$ \\
\hline \multicolumn{8}{|c|}{2012} \\
\hline Variável & Mínimo & Máximo & Média & Mediana & Moda & Desvio Padrão & $\begin{array}{l}\text { Coeficiente de } \\
\text { Variação }\end{array}$ \\
\hline Tamanho & 1 & 8 & 3,19 & 3,00 & 3,00 & 1,16 & $36,4 \%$ \\
\hline Independência & 1 & 7 & 2,98 & 3,00 & 3,00 & 1,07 & $35,8 \%$ \\
\hline Expertise & 0 & 4 & 1,19 & 1,00 & 1,00 & 1,00 & $84,0 \%$ \\
\hline \multicolumn{8}{|c|}{2013} \\
\hline Variável & Mínimo & Máximo & Média & Mediana & Moda & Desvio Padrão & $\begin{array}{l}\text { Coeficiente de } \\
\text { Variação }\end{array}$ \\
\hline Tamanho & 1 & 8 & 3,25 & 3,00 & 3,00 & 1,17 & $35,9 \%$ \\
\hline Independência & 1 & 8 & 3,10 & 3,00 & 3,00 & 1,14 & $36,8 \%$ \\
\hline Expertise & 0 & 4 & 1,22 & 1,00 & 1,00 & 1,07 & $87,5 \%$ \\
\hline
\end{tabular}

Nota. Fonte: Dados da pesquisa.

Observa-se na Tabela 6 que o tamanho do comitê de auditoria varia entre as empresas que possuem 02 membros no referido comitê e as empresas que possuem até 09 membros em 2010, e de 01 a 08 membros nos anos posteriores. Considerando a média, nota-se que a maioria das organizações possui comitê de auditoria com aproximadamente 03 membros. A Lei Sarbanes Oxley, Instruções da CVM (2002), CMN (2004) e os estudos de Yang e Krishnan (2005) afirmam que o comitê de auditoria deve ser formado por no mínimo 03 membros indicados pelo Conselho de Administração. Porém, ao analisar o desvio padrão e o coeficiente de variação apresentados no período, observa-se que a amostra é heterogênea, ou seja, existe uma grande dispersão e baixa concentração de dados em torno da média. Portanto, há uma grande quantidade de valores que diferem da média. Visto a fragilidade da média, confirma-se a quantidade de membros nos comitês por meio da análise da mediana e da moda. Todos os anos pesquisados apontam que o tamanho do comitê é de 03 membros, conforme recomendado pela legislação apresentada. Tem-se, assim, que em se tratando da característica: tamanho, há uma conformidade e aderência à legislação e recomendações vigentes. 
Quanto à variável independência constata-se que há organizações que possuem até 07 membros independentes em seus comitês de auditoria nos anos de 2010 a 2012, e até 08 membros em 2013. A independência dos membros do comitê é recomendada por órgãos como IBGC e CVM. Klein (2002) constatou que quanto maior o número de membros independentes que um comitê possui, melhor a qualidade da informação disponibilizada ao usuário. Ao analisar a média do período tem-se que em todos os anos pesquisados houve em torno de 03 membros com independência de outros comitês ou órgãos vinculados à organização. Porém, essa percepção não é homogênea, visto que o coeficiente de variação foi maior que $30 \%$ e o desvio padrão praticamente não se alterou no decorrer dos anos pesquisados, atrelando a essas amostras uma alta dispersão dos dados e um distanciamento de informações próximas à média encontrada. Contudo, observa-se que três membros foi o número mais encontrado na maior parte das empresas investigadas.

Ao analisar a expertise dos membros do comitê de auditoria percebe-se que a maioria das empresas possui pelo menos um membro com expertise em contabilidade, finanças ou auditoria, conforme recomendações do IBGC (2009a). Ika e Ghazali (2012) também afirmam que a formação e experiência na área contábil, auditoria e finanças influenciam na eficiência do comitê de auditoria. A dispersão na quantidade de membros com essa expertise varia de zero a seis membros em 2010 e quatro membros nos anos seguintes. A média apresentada em todos os períodos confirma que existe pelo menos um membro com o conhecimento necessário na composição dos comitês de auditoria. No entanto, a estatística descritiva evidencia uma amostra heterogênea, ao apresentar um desvio padrão e coeficiente de variação elevado. Assim, a amostra é heterogênea nesse quesito. A partir da moda, observase que um membro foi o valor mais encontrado nos anos pesquisados. Desse modo, percebese que no que tange à expertise, algumas empresas não estão em conformidade com as práticas recomendadas.

Ao verificar os resultados obtidos, nota-se que a maior parte das organizações contempladas neste estudo atende às especificações recomendadas em estudos anteriores e legislação vigente. Demonstra-se que as características: tamanho, independência e expertise são predominantes em todas as empresas que possuem o comitê de auditoria formalizado. Contudo, há aquelas que não atendem aos preceitos mínimos das práticas recomendadas, no que concerne ao tamanho, independência e expertise.

\section{CONCLUSÃO}

O estudo objetivou verificar as características de tamanho, independência e expertise dos comitês de auditoria das empresas listadas na BM\&FBovespa nos anos de 2010 a 2013. Dentre as 407 empresas listadas na bolsa de valores, apenas 68 delas possuem comitê de auditoria devidamente formado em algum período analisado. O ano de 2013 apresentava 59 empresas com comitê de auditoria. Foi esse o maior número encontrado, o que representa apenas $14,50 \%$ da população. A maioria dessas empresas pertence ao Novo Mercado, no que diz respeito às categorias de governança corporativa, e abrange principalmente os setores de utilidade pública, consumo cíclico, consumo não cíclico, construção e transporte e materiais básicos.

Os principais resultados mostraram que em relação ao tamanho a maior parte obedece aos preceitos das práticas recomendadas, ou seja, possuem três membros participantes do comitê de auditoria. Contudo, as empresas apresentam práticas heterogêneas nessa característica. Existem tanto aquelas com apenas um ou dois membros como outras que possuem mais de seis membros. Em relação à independência, a maioria das empresas investigadas têm dois ou três membros considerados independentes, o que atende às boas práticas de governança corporativa. Entretanto, observaram-se poucos membros ativos nestes comitês com formação em Contabilidade e experiência em Auditoria. Em 2013 existiam 192 membros dos comitês de 59 empresas. Desses, 25\% são engenheiros e 21,35\% administradores. Uma das funções deste comitê refere-se à análise das demonstrações contábeis e procedimentos de controle interno, o que requer conhecimentos mais específicos. Nesse sentido, a expertise se caracteriza pelo conhecimento em contabilidade, auditoria e 
finanças. Em 2013 participavam do comitê um auditor, 26 contadores e 45 economistas, o que representa $0,52 \%, 13,54 \%$ e $23,44 \%$, respectivamente, em relação ao total dos participantes.

De modo geral, conclui-se que a criação do comitê de auditoria ainda não é uma prática institucionalizada pelas empresas brasileiras e que esse se manifesta de formas distintas entre as organizações. O estudo contribuiu para reforçar os resultados de pesquisas já realizadas acerca do tema, além de estender a compreensão sobre as características presentes nos comitês de auditoria de empresas brasileiras, e, principalmente, oferece alguns insights para pesquisas futuras.

Nesta pesquisa, investigaram-se as empresas não financeiras listadas na BM\&FBOVESPA, sem fazer qualquer distinção nos resultados por setor específico. Assim, sugere-se um aprofundamento do estudo contemplando o setor financeiro e a comparabilidade da amostra. Outra sugestão é a realização de estudos com o intuito de compreender as razões pelas quais as empresas não institucionalizam os comitês de auditoria em suas organizações. Além disso, um estudo específico poderia investigar os motivos das empresas eliminarem o comitê já criado anteriormente, como foi o caso de nove empresas brasileiras. A pequena parcela de empresas com comitês de auditoria causa algumas inquietações acerca da sua efetividade. Por que as empresas brasileiras não possuem comitês de auditoria nos seus organogramas? Quais são as resistências para a formação desse órgão? Qual é efetivamente o papel desse órgão nas empresas brasileiras? Assim sendo, as funções e atividades exercidas por tais comitês também podem ser objeto de investigação, para cotejar com o que a literatura preconiza. Além disso, a pequena quantidade de membros com formação em contabilidade também instiga estudos futuros.

\section{REFERÊNCIAS}

Adelopo, I., Jallow, K., \& Scott, P. (2012). Multiple large ownership structure, audit committee activity and audit fees: Evidence from the UK. Journal of Applied Accounting Research, 13(2), 100-121.

Baioco, V. G., \& Almeida, J. E. F. (2017). Efeitos do comitê de auditoria e do conselho fiscal na qualidade da informação contábil no Brasil. Revista Contabilidade \& Finanças - USP, 28(74), 229-248.

Beuren, I. M., Nass, S., Theiss, V., \& Cunha, P. R. (2013). Caracterização proposta para o comitê de auditoria no Código de Governança Corporativa do Brasil e de outros países. Revista de Educação e Pesquisa em Contabilidade, 7(4), 407-423.

Bolsa de Mercadorias \& Futuros BOVESPA. (2015). Diretrizes de governança corporativa. São Paulo: BM\&FBOVESPA. Recuperado de http://ri.bmfbovespa.com.br/fck_temp/26_2/Diretrizes_de_Governanca_Corporativa_da_B MFBOVESPA.pdf

Bolsa de Mercadorias \& Futuros BOVESPA. (2014). Segmentos de listagem: novo mercado. Recuperado de http://www.bmfbovespa.com.br/pt_br/listagem/acoes/segmentos-delistagem/novo-mercado/

Comissão de Valores Mobiliários. (2002). Recomendações da CVM sobre governança corporativa. Recuperado de http://www.cvm.gov.br/

Conselho Monetário Nacional (2004). Resolução n. 3.198, de 27 de maio de 2004, altera e consolida a regulamentação relativa à prestação de serviços de auditoria independente para as instituições financeiras, demais instituições autorizadas a funcionar pelo BACEN e para as câmaras e prestadores de serviços de compensação e de liquidação. Recuperado em 11 abril, 2015, de https://www3.bcb.gov.br/normativo/detalharNormativo.do?N=104080599\&method=detalha rNormativo 
Cunha, P. R., Hillesheim, T., Faveri, D. B., \& Rodrigues Junior, M. M. (2014). Características do comitê de auditoria e o gerenciamento de resultados: um estudo nas empresas listadas na BM\&FBovespa. Revista de Contabilidade e Organizações, 8(22), 15-25.

Cunha, P. R., Lunelli, L. O., Santos, V. D., Faveri, D. B., \& Rodrigues Junior, M. M. (2015). Relação entre as Características do Comitê de Auditoria e o Atraso da Emissão do Relatório da Auditoria Independente (Audit Delay). Contabilidade, Gestão e Governança, 18(3), 47-65.

Cunha, P. R., Sant'ana, S. V., Theis, M. B., \& Krespi, N. T. (2013). Características do Comitê de Auditoria e os reflexos no gerenciamento de resultados nas empresas listadas na BM\&FBovespa. Revista de Contabilidade do Mestrado em Ciências Contábeis da UERJ, 18(3), 2-19.

Cunha, P. R., Pletsch, C. S., \& Silva, A. (2015). Relação entre as Características da Empresa, do Comitê de Auditoria e do Auditor Independente com o Prazo de Publicação das Demonstrações Financeiras. Revista de Educação e Pesquisa em Contabilidade, 9(4), 415-429.

Dezoort, F. T., Hermanson, D. R., Houston, R. W. (2003). Audit committee support for auditors: The effects of materiality justification and accounting precision. Journal of Accounting and Public Policy, 22(2), 175-199.

Felo, A. J., Krishnamurthy, S., \& Solieri, S. A. (2003). Audit committee characteristics and the perceived quality of financial reporting: an empirical analysis. Working paper, Penn State Great Valley, 2003.

Habbash, M., Sindezingue, C., \& Salama, A. (2013). The effect of audit committee characteristics on earnings management: Evidence from the United Kingdom. International Journal of Disclosure and Governance, 10(1), 13-38.

Instituto Brasileiro de Governança Corporativa. (2009a). Guia de Orientação para melhores práticas de Comitês de Auditoria. Cadernos de Governança Corporativa. São Paulo: IBGC. Recuperado de http://www.ibgc.org.br/userfiles/files/Guia_7_.pdf

Instituto Brasileiro de Governança Corporativa. (2009b). Código das Melhores Práticas de Governança Corporativa. (4a ed.) Instituto Brasileiro de Governança Corporativa. São Paulo, SP: IBGC Recuperado de http://www.ibgc.org.br/userfiles/2014/files/codigoMP_5edicao_web.pdf

Ika, S. R., Ghazali, N. A. M. (2012). Audit committee effectiveness and timeliness of reporting: Indonesian evidence. Managerial Auditing Journal, 27(4), 403-424.

Klein, A. (2002). Audit committee, board of director characteristics, and earnings management. Journal of Accounting and Economics, 33(3), 375-400.

Lary, A. M., \& Taylor, D. W. (2012). Governance characteristics and role effectiveness of audit committees. Managerial Auditing Journal, 27(4), 336-354.

New York Stock Exchange - NYSE. (2003). Commitee Recomendation. New York. Recuperado de https://www.nyse.com/publicdocs/nyse/regulation/nyse-american.pdf

Oliveira, M. C. \& Costa, P.P. (2005). O comitê de auditoria nas companhias abertas brasileiras: um estudo multicaso. Anais do Congresso USP, São Paulo, Brasil. Recuperado em http://www.congressousp.fipecafi.org/web/artigos52005/24.pdf

Valor 1.000: 1.000 maiores empresas (2014). Revista Valor Econômico, São Paulo, 14, (14). Recuperado de http://www.valor.com.br/valor1000/2014/ranking 1000maiores

Silveira, A. D. M. D., Barros, L. A. B. D. C., \& Famá, R. (2003). Estrutura de governança e valor das companhias abertas brasileiras. Revista de Administração de Empresas, 43(3), 5064. 
Sorrentino, M. S. A. S., Teixeira, B., \& Vicente, E. F. R. (2016). Comitê de Auditoria: adequação às regras da SOX, Bacen, Susep e IBGC. Revista de Educação e Pesquisa em Contabilidade, 10(3), 241-257.

Teixeira, B., Camargo, R. V. W., \& Vicente, E. F. R. (2016). Relação entre as Características do Comitê de Auditoria e a Qualidade da Auditoria Independente. Revista Catarinense da Ciência Contábil,15(44), 60-74.

Viana, E. (2010). A governança corporativa no setor público municipal: um estudo sobre a eficácia da implementação dos princípios de governança nos resultados fiscais. Dissertação de Mestrado, Universidade de São Paulo, Ribeirão Preto.

Yang, J. S., \& Krishnan, J. (2005). Audit committees and quarterly earnings management. International Journal of Auditing, 9(3), 201-219. 